\title{
THE EFFECT OF INFORMATION TECHNOLOGY ON THE COOPERATIVE INSURANCE INDUSTRY CASE STUDY: SHIEKAN INSURANCE AND REINSURANCE COMPANY - SUDAN (EMPIRICAL STUDY)
}

\author{
Dr. Omer Ali Babiker Eltahir \\ Assistant Professor -Business Administration Department \\ Darb University College- Jazan University-KSA \\ Email: obabiker@jazanu.edu.sa oeltahir@hotmail.com
}

\begin{abstract}
This study aimed to investigate the effect of information technology on the cooperative insurance industry, Shiekan Insurance and Reinsurance Company Sudan as a case study. The study has achieved in the hypothesis that there is a strong positive relationship between the application of information technology system and the development of management and performance of Shiekan Insurance Company. The study found that the majority of dealers in the Sudanese insurance market have weak in dealing with technology. The study concluded that there a clear impact of information technology and achieving a competitive advantage of Shiekan Insurance company. The study recommends the need to move to the use of technology in the insurance sector in Sudan, especially in the Shiekan Insurance Company because it will have a clear impact on the speed of completion of transactions and claims and save costs.
\end{abstract}

Keywords: $\quad$ Sudan, Reinsurance, Cooperative Insurance, Information Technology, Shiekan

\section{Introduction}

The protection of the local economy is not easy on the role of any organization, whatever the privileges granted to them and the degree of economic progress of any country depends primarily on the degree of progress banks and insurance industries and their development.

Financial services sector witnessed the use of large-scale technology in the core activities of the day. Insurance is a form of comfort and peace of mind and security for commercial activities, industrial, service and others. It has a big role in the development of these activities and other economic activities, so it is a modern means of task involved in the system of economic regulation and financial.

Presently, traditional distribution channels still occupy the largest share of the market, where they have achieved significant economies of scale. With the increasing various risks factors importance of purchasing different products of insurance are also on rise. Insurance institutions (insurance companies) has occurred not only protection for the economy but beyond that contribute to the financing of the economy. Cooperative insurance one of the types developed in the insurance sector.

Over the last few years, many insurance firms have expanded, and enhanced the way their customers are buying insurance (Annette Gannon, Jul 24, 2018). People are demanding a change from the more traditional way of purchasing coverage to a method that is faster and more convenient for them.

Information technology plays an important role in the financial \& banking sector and its development. This study came to know the impact of information technology on the cooperative insurance sector "Shiekan Insurance and Reinsurance Company- Sudan" as a case study. 
International Journal of Economics, Business and Accounting Research (IJEBAR)

Peer Reviewed - International Journal

Vol-4, Issue-1, 2020 (IJEBAR)

E-ISSN: 2614-1280 P-ISSN 2622-4771

https://jurnal.stie-aas.ac.id/index.php/IJEBAR

\section{Theoretical Background \\ Concepts}

Information Technology is the definition of the word TECHNOLOGY which is derived from the Greek word TECHNE means technical skills or second part of the word, which means LOGY note or study while some see as a culture ( IT concept, 2012).

IT can be defined as procedural means everything used in the field of education of information technology, such as using computer networks, local and global (Internet) with the aim of storing, processing and retrieval of information all the time and at any time.

Accordingly, information technology is in its broadest sense planning, preparation, development, implementation and complete evaluation of the educational process in all its aspects, and through various technical means that all work in harmony with the human elements to achieve education goals.

Cooperative insurance is the participation of a group of people with non-profit amounts on the donation party, which is allocated to compensate those who are harmed by them. It is not profit and material gain (Sadiqy, Muhammad Najatullah,1990).

\section{Information Technology in Insurance (Importance \& Role)}

The financial services sectors have seen widespread use of technology in core activities today. The banking industry and the insurance sector have provided their entire processes automatically to help better serve their customers. Technology and insurance have gone hand in hand to make complex areas of insurance business faster and smoother through automated claims processing systems.

The use of the latest information technology applications in the insurance sector provides accurate and instantaneous information on various insurance for clients. Insurance companies usually and regularly spend part of their annual premiums to bring in modern technology that helps to boost the overall performance of companies. Insurance techniques help insurance agents to respond immediately to customer requirements, and the technology used when well managed works to reduce the annual expenses of these companies.

The information technology in the insurance field has also made the insurance sector significantly reduce the amount of paperwork that was used to use another method of managing and storing all data. With security software systems and their various applications, a minimum level of paper is now used in performing insurance operations, making them environmentally friendly solutions. Less documentation means less manual work. IT in Insurance has two benefits, fewer opportunities for errors in data processing, and service provision, and manual labor, which is a costly matter that can be used in other areas more important than customer support and the service provided (Information Technology in the Insurance Sector, Gregory Gambone). Insurance technology, which developed from the Internet insurance system, has been driving innovation and development throughout the entire insurance industry.

One of the most important roles of information technology in the field of insurance is that it helps companies reduce costs by eliminating mail rooms and paper files as well as data accessory. The process of data processing and classification is done via the Internet, on which clients and brokers receive documents and papers on insurance policy and documents via e-mail in a short time. The information technology system in the insurance field requires large investments in its initial stages, but the company is getting returns for sure on these investments over the coming years that come with superior services and quick response time to perform the work (The role of IT in Insurance, Chris Mackechnie). 
Information technology has a role in the insurance sector, as it simplifies and speeds up the process of purchasing and renewing policies (insurance policies). For clients: Provides the convenience and confidence of purchasing an insurance policy online or providing electronic payment, which leaves more time for the completion of work tasks, family needs, or other tasks. For insurance companies: electronic invoices save money. Computerized customer databases: Allow sales agents, and customer service representatives to answer questions more quickly and help customers make policy change or cancel any service immediately.

The role of information technology emerges as a means of motivation, by helping it to provide the decision maker with reports on the levels of performance achieved, so that he/she can finally compare his/her decisions with his/her accomplishments, or by comparing his/her accomplishments with those of his/her counterparts, and thus has an idea of the degree of his/her competence at work in general, particular in decision-making, and this will undoubtedly constitute a moral incentive, but in an indirect way. Information in general help to understand the model of organization in which people represent active parts in, also information provides psychological comfort, especially when the deviations in performance coincide with the permissible limits it out for distractions.

As a result, the role of insurers is morphing from one solely concerned with loss indemnification to a broader advisory service for insureds on how to prevent, mitigate and manage their risks. This will have implications for insurers' business models, how they interact with their customers and the nature of the products and services they provide.

\section{Advantages \& Disadvantages of applying Information Technology in the Insurance Sector}

With increased competition among insurance companies, service has become a major issue. Moreover, customers have become more sophisticated, dealing and knowledgeable about technology. Today, people want personal interaction, looking for more features and adding better services so insurance companies must work to meet the need for a more personal approach to deal with customers. Intelligent customer management is an extremely important to an insurance company, especially in a competitive environment and also to implement a different set of rules and strategies for dealing with different customer segments. However, obtaining customer information and storing it in an integrated system (The use of IT in Insurance, Steve Glenn).

Traditional intermediaries still represent the dominant channel through which insurance policies are sold. In these areas, technology is being applied to improve the efficiency and effectiveness of agents and brokers.

Distribution channels are responding to changes in consumer preferences. Price comparison websites, which have been around for quite some time, are providing consumers with more information on products and costs, especially for more commoditized products like auto and travel insurance. They often sell a product directly with no agent or broker involvement. Modern consumers are more self-directed in their insurance decisions and want to interact through various channels when researching and buying insurance.

The information technology application in the insurance sector allows insurance companies to increase revenues by automating service processes that were cumbersome and take a long time as the process of creating these documents was being accomplished by armies of technicians, clerks, and stamps, so this task has become easy to use technology because it's customer data kept in huge databases, accessed by computer systems and information about documents collected using advanced software packages and printed using high-speed printers.

As for insurance agents, they can sell more insurance policies, offer and study more orders for new customers, thus create opportunities to buy faster. It also makes it easier for clients through 
the insurance agents' websites to complete orders and purchases, sign policies and documents, know the conditions, and receive claims without having to visit the insurance agency in person (Advantages and disadvantages of information technology, Karehka Ramey,2012) .

Policy and claims management is also becoming more efficient, as machine learning and pattern recognition are used to analyze handwritten and unstructured documents to expedite and detect false claims. Insurers are also experimenting with Block-chain technology - digital distributed ledgers which are cryptographically secure - to improve the efficiency of processes within and among existing institutions, such as in claims management or reinsurance contracts. Here Blockchains offer benefits of speedier connectivity between counterparties and potential for reduced fraud or loss adjustment expenses, all of which help lower insurers' overall costs (Technology and insurance: themes and challenge, june, 2017).

Also, insurance companies that have an online presence and those that do marketing on the World Wide Web are targeting a specific audience that deals with the Internet and therefore neglects who is not dealing with the Internet or who does not now dealing with the computer and its software (computer illiteracy) This is one of the disadvantages of applying information technology to the insurance sector.

Developments in the Internet and other related information technologies have greatly improved consumers' access to information. However, the Internet channel is still relatively weak in terms of its display of complex insurance products(InsurTech: Infrastructure for New Insurance, KPMG CHINA Insurance Service, 2019). The online availability of complex products needs to be further improved. This situation stems from the fact that complex products are generally priced higher. Also, current technology has not been able to significantly improve customers' perception of complex products and the availability of such products (Technology and insurance: themes and challenge, june, 2017). Finally, customers' awareness of the Internet channel and their trust in it need to be further developed.

\section{Difficulties facing the traditional Insurance Model}

- Products are homogeneous and do not sufficiently meet consumer demands.

- Insurance companies' ability to control cooperative channels is weak, and customer acquisition costs are relatively high( InsurTech: Infrastructure for New Insurance, KPMG CHINA Insurance Service, 2019).

- Profitability in underwriting is relatively low, and long-term development is limited.

\section{Impact of Information Technology on Insurance Sector}

A premium of insurance companies is always based on the possibility that the customer has suffered a loss. Originally, valuation experts study the trends and history of claims to determine rates using information technology. For example, homes close to the site of a fire or from a fire water pipe were more susceptible to fire damage than those with protection.

Technology has enabled assessment experts to create more accurate models, and to follow trends such as knowing the water pressure in faucets in different neighborhoods, the quality of training in the fire department, and adding a fire alarm at home. The result is an understanding of the risks inherent in the premium account and the ability to determine the appropriate premium for that policy. This has an impact for information technology on the insurance sector (The Effects of Technology on the Insurance field, Chris Mackechnie).

Gradual insurance is one of the mean. Sometimes the auto claim is settled while the car is still at the scene of the accident. Preparing the claims provides better service to customers and reduces 
expenses for the insurance company. This also has an impact on information technology on the insurance sector (Abdul Motin, Ostagar, 2018).

Mobile technology has an additional effect on insurance, as customers who use smartphones can connect to the Internet from anywhere, and can pay, report, and claim to the insurance company as they happen. Smartphones and digital cameras allow customers to take photographs of damage that can be helpful in the event of storm damage such as home damage or a car accident covered by the insurance policy (Sherif Mahmoud Radwan, Jan 2019).

Mobile technology also allows insurance companies to send alerts to customers to inform them of upcoming due dates for insurance premiums, and reduce the possibility of late payment, and coverage gaps.

The information technology has a huge impact on the insurance industry (Information Technology in Insurance, Devipriya et al):

- Productivity and efficiency.

- Communication with the policy holders.

- E policies.

- Premium payment.

- Tax certificate Income.

- Automatic issuance of non-medical policies.

Impact of Information Technology on the Cooperative Insurance Sector Shiekan Insurance \& Reinsurance Company - Sudan (Empirical Study).

It can be said that the Islamic world did not know insurance in its organized form until the second half of the twentieth century, just as the experience in Sudan, which has known the insurance industry for more than fifty years and in many parts of the Islamic world did not gain the required popularity.

The need for Islamic cooperative insurance in Sudan emerged in the year 1978 AD when the Sharia Supervisory Authority of Faisal Islamic Bank of Sudan, which included a number of Islamic and Sharia law scholars, declared that the bank's property may not be insured with commercial insurance companies and obliged the bank to deal with Islamic cooperative insurance companies, and the authority adopted in its fatwa the existence of ambiguity in the financial netting contracts, of which insurance represents one of the precursors that it includes and forbidden by ambiguity. It is prescribed in the hadith of the Messenger, may God's prayers and peace be upon him, that a number of trusts narrated about him.

The actual application of Islamic insurance in Sudan has started for the first time in the Islamic world and the experiment achieved great success, which led the pioneers of the insurance industry in Sudan to develop it in line with the necessities of the times, in line with the requirements of Islamic Sharia, the establishment of Sharia Supervisory Bodies is charged with sponsoring the experiment and monitoring the performance of the bodies, so, it implements and always ensures that work in the insurance field is carried out in accordance with the provisions of Islamic Sharia.

In Sudan, more than half a century has passed since insurance entered the country. Throughout the past years, the Sudanese insurance industry was proceeding at a slow pace where only traditional insurance was practiced in a weak form, and this may have its logical reasons as people were reluctant to insurance due to Poetic embarrassment, as there are citizens who had a belief in the prohibition of insurance and its violation of the provisions of Islamic Sharia (Shiekan Insurance and Reinsurance Company, Brochure). 


\section{International Journal of Economics, Business and Accounting Research (IJEBAR) \\ Peer Reviewed - International Journal \\ Vol-4, Issue-1, 2020 (IJEBAR) \\ E-ISSN: 2614-1280 P-ISSN 2622-4771 \\ https://jurnal.stie-aas.ac.id/index.php/IJEBAR}

Weak economy, as the country was until recently dependent on its national income for agricultural and animal products, while industrial production remained underdeveloped because of weak energy resources from electricity and the lack of foreign investment or the exploitation of part of it in failed projects that kept the country's economy is something are still suffering from, perhaps for many years.

Because of external debts and low interest rates, consumed the public treasury and reduced the state's ability to establish development projects that help increase national income. Political instability, governments 'succession, changing economic policies from time to time, and the consequent weakness of development in the country, lack of employment opportunities, and low income so that the average citizen cannot fulfill his daily obligations, let alone exchange on purchasing insurance policies (Shiekan Insurance and Reinsurance Company, Brochure).

\section{Shiekan Insurance \& Reinsurance Company - Sudan Company (case study)}

To take Shiekan as a case study, the company was contacted and approval was taken. The company's management expressed all cooperation by giving information and answering the questions about the study by the top management represented by the Deputy Director Manager who issued directives to departments to help, also with encouragement and help of the Assistant general Manager who answered the questions through which the hypotheses studied, found the results and recommendations.

The most important gains that have been achieved under the application of a modern technical system in Shiekan Insurance Company partly by $50 \%$ as stated by the company's management, that the Shiekan company has increased its use of information technology from the volume of issuances, especially the versions of cars with a large number (vehicles And buses, trucks, private cars and public service cars), given that $75 \%$ of the total Sudanese insurance market issues for this type are issued by Shiekan Company and the company's share in the Sudanese insurance market ranges between (70-75\%) (www. sheikanins.sd).

The company's management response that the introduction of computers and information technology in the issuance led to a reduction in the administrative expenses of the Shiekan company and a decrease in dependence on reinsurance, as it decreased from $42 \%$ to $25 \%$, and the most important advantages and gains that were achieved from the application of technology (www. sheikanins.sd).

The information in the company contributed to the elimination of the phenomenon of forgery and tampering with auto documents, which was largely prevalent in the Sudanese insurance market when using the traditional method of issuance, which drained the liquidity of insurance companies, and this is a gain that resulted from the use of information technology in the insurance sector using Confidential figures for these releases.

To identify the most important problems and obstacles facing the application of information technology in the company in full, was the lack of familiarity with clients to deal with the company, other insurance companies in the Sudanese market who is dealing with computers and information technology applications, in addition to a low percentage Insurance awareness in Sudan, as well as twice the size of the premiums. Sudan is ranked third before the last in terms of the size of premiums among Arab countries (Shiekan Insurance and Reinsurance Company, Brochure).

The high operating cost of technology, incomplete interconnection of the computer network to head the company, its branches and agents is also a result of poor insurance premiums in Sudan, as well as the lack of qualified personnel to deal with this software, which needs training in operation, maintenance and development. 
International Journal of Economics, Business and Accounting Research (IJEBAR)

Peer Reviewed - International Journal

Vol-4, Issue-1, 2020 (IJEBAR)

E-ISSN: 2614-1280 P-ISSN 2622-4771

https://jurnal.stie-aas.ac.id/index.php/IJEBAR

\section{Methodology}

The study hypotheses are trying to validate the basic assumptions and hypotheses:

Hypothesis 1: There is a statistically significant relationship between the application of information technology and the performance, management development of Shiekan Insurance \& Reinsurance Company ( case study ) .

Hypothesis 2: There is a statistically significant relationship between the applications of information technology and achieving a competitive advantage in Shiekan

Sub- hy potheses:

Insurance \& Reinsurance Company (case study).

The first Sub- Hypothesis: There is a statistically significant relationship between the uses of information technology and improving the level of services provided by the Shikan Insurance \& Reinsurance Company (case study).

The second Sub- Hypothesis: There is a statistically significant relationship between the shift to information technology and increasing revenues and profits of Shiekan Insurance \&Reinsurance Company (case study).

\section{Statistical analysis of the study}

This section includes the display and analysis of the data accumulated by the researcher through the questionnaire that was distributed to respondents of all individuals; in this study "The effect of information technology on the cooperative insurance sector Shaikan Insurance and Reinsurance Company - Sudan " (Empirical Study). Following are results:

The results concerning the test of hypotheses of the study:

Main Hypothesis 1: There is a statistically significant relationship between the application of information technology and the performance, management development of Shiekan Insurance \& Reinsurance Company (case study).

\section{Subdivided into the sub-hypothesis:}

The first Sub- Hypothesis: There is a statistically significant relationship between the uses of information technology and improving the level of services provided by the Shikan Insurance \& Reinsurance Company (case study).

The results of the application of multiple regression equation to study the relationship between the application of information technology and the performance, management development of Shiekan Insurance \& Reinsurance Company:

- The study concluded that there is a statistically significant relationship at the significance level $(\alpha \leq 0.05)$ that the application of information technology in Shiekan Insurance \& Reinsurance Company has contributed to controlling the administrative, technical and accounting performance of the company. On one hand, the company's employees contributed to determining the user's name electronic system, which helped to control the performance of claims employees and the speed of completing the claim in a short time, where values of $(B, T)$ reached $(0.38,3.08)$, respectively, a statistically significant values.

- On the other hand, the company's clients contributed to determining the customer's name in the system, which led to knowing the record of fulfilling the current installments and previous years according to the schedule, and also knowing his record of claims according to previous years with the necessary speed, and therefore had a great impact on the 
development of management in Shaikan Insurance Company and their interest in speed completing transactions and attracting more customers.

- The sub-hypothesis states there is a relationship between the use of information technology and the improvement in the level of services provided by Sheikan Insurance Company also significant at the significance level $(\alpha \leq 0.05)$. The study found that there has been an improvement in the level of services provided as a result of the use of information technology helped to exchange information and obtain survey reports for the risk to be secured with all ease and ease, which contributed to controlling the time required to complete the service and improving its level, which reflected positively on customers and led to protecting the company and the customer from any insurance gap. Where values of ( $B$, $\mathrm{T})$ reached $(0.24,2.24)$, respectively, a statistically significant values.

- There is a statistically significant relationship at the significance level $(\alpha \leq 0.05)$ between the application of information technology and the performance, management development of Shiekan Insurance \& Reinsurance Company, as the value of the correlation coefficient (R) was (0.74), a value statistically significant which indicates the degree of correlation between the independent variables and dependent variables, and the value of (R-square) was (0.547), a statistically significant value explains the relationship between the application of information technology and the performance, management development of Shiekan Insurance \& Reinsurance Company, and the test value (F) was of (13.126) a statistical significant value of (0.00), a statistically significant value at the significance level $(\alpha \leq 0.05)$ indicate of a statistically significant relationship between the independent variable and dependent variables, therefore, accepts the hypothesis .

Main Hypothesis 2: There is a statistically significant relationship between the applications of information technology and achieving a competitive advantage in Shiekan Insurance \& Reinsurance Company (case study).

\section{Subdivided into the sub-hypothesis :}

The second Sub- Hypothesis: There is a statistically significant relationship between the shift to information technology and increasing revenues and profits of Shiekan Insurance \&Reinsurance Company (case study).

The results of the application of multiple regression equation to study the relationship between the applications of information technology and achieving a competitive advantage in Shiekan Insurance \& Reinsurance Company:

- Likewise, upon testing the other main hypothesis, which states that there is a statistically significant relationship at the significance level $(\alpha \leq 0.05)$ between the application of information technology and achieving a competitive advantage in Shiekan Insurance \&Reinsurance Company. The study concluded that the use of information technology contributed to obtaining the specifications of the tenders for the risks to be secured in a timely and necessary speed, which enables Shiekan Insurance \& Reinsurance Company from carefully examining the risk, setting prices and conditions for coverage, as well as making the necessary contacts with reinsurers to ensure the coverage of amounts that exceed the limits of the agreement and what kind of risk is required to be covered from a portion of it optionally. Where values of $(B, T)$ reached $(0.344,6.263)$, respectively, which is a statistically significant values. 
- The sub-hypothesis that states there is a relationship between the shift to information technology and the increase in revenues and profits of Shiekan Insurance \& Reinsurance Company also significant at the significance level $(\alpha \leq 0.05)$, it became clear from the study that the use of information technology may be little has contributed to attracting a number of customers, especially large companies and factories operating within the framework of the investment boom that was in the country. Where values of $(\beta, T)$ reached $(0.285,4.505)$, respectively, a statistically significant values.

- There is a statistically significant relationship at the significance level $(\alpha \leq 0.05)$ between the application of information technology and achieving a competitive advantage in Shiekan Insurance \&Reinsurance Company, as the value of the correlation coefficient (R) was (0.71), a value statistically significant which indicates the degree of correlation between the independent variables and dependent variables, and the value of ( $\mathrm{R}$-square) was (0.504), a statistically significant value explains the relationship between the application of information technology and achieving a competitive advantage in Shiekan Insurance \&Reinsurance Company, and the test value (F) was of (26.07) a statistical significant value of (0.00), a statistically significant value at the significance level $(\alpha \leq 0.05)$ indicate of a statistically significant relationship between the independent variable and dependent variables, therefore, accepts the hypothesis .

\section{Results and Discussion}

Through the study and analysis of the application of information technology on management and performance development of Shiekan Insurance and Reinsurance Company. The study found the following results:

a. There was a clear impact of information technology on developing the management and performance of Shiekan Insurance and Reinsurance Company, by achieving many gains and advantages for the company due to the current partial application of information technology in completing its transactions.

b. Shiekan Company has increased its reputation among the insurance companies operating in the Sudanese insurance market and among the dealers in this industry, and its competitive advantage has been achieved after its shift towards information technology.

c. The revenues and profits of Shiekan Insurance and Reinsurance Company have increased, albeit slightly, after its partial technological transformation.

d. The level of services provided by this company has increased in quality and improvement after modern technological application, despite the problems and obstacles that accompanied the application of information technology in the company.

e. Shiekan Company has become far from the traditional methods of management and the completion of transactions in its field as much as it is careful use of information technology in its various affairs and activities that it aspires to shift towards full information technology (starting from learning about the company's services and types of documents, policies and conditions, submitting requests, approving, signing the policy, issuing and sending it, and completing the procedures for paying the installments, mentioning their dates, claims, settling them automatically without the need for the customer to direct the company's offices and other uses of modern technological means).

f. In addition, the study found that the technology revolution and the use of the Internet helped a lot in exchanging information between insurance companies and re-insurance companies by renewing agreements easily, assigning optional coverage, which became complete in a short time, and with reasonable administrative expenses compared to what was prevailing 
before that, each had a direct impact on the improvement in the level of services provided by Shiekan Insurance Company to its clients.

g. Accordingly, the study finds that the speed and discipline in exchanging information with customers by information technology has contributed effectively to attracting insurance and thus increasing the size of the subscription and by applying information technology to the insurance market in full, it avoids harmful competition between companies and maintains the rate of prices and finds the necessary protection for customer properties, and with Partial application of Shiekan company for information technology in its transactions from obtaining insurance offers and filling insurance applications.

h. Issuing the document through the computer with a dedicated program and processing claims except that it has contributed to achieving the company's competitive advantage in the market Sudanese insurance, as $75 \%$ of the total versions of the Sudanese insurance market for vehicles are issued by Shiekan Company, in addition to some Embassies in Sudan, United Nations organizations operating in Sudan, oil and communications companies, large factories and strategic facilities such as oil refineries, oil and electricity pipelines, and banks issue their insurance with the Shiekan company.

i. The company believes that the quality of clients dealing with the company, which represents $75 \%$ of them, the company's versions of the auto branch (except for a few) can continue at the present time because the largest volume of issues with individuals can continue in the traditional way of completing transactions in the sense of obtaining insurance offers and requesting insurance automatically or traditionally, approving the insurance request traditionally, issuing the document automatically, receiving the policy traditionally and settling claims.

j. Also, with reference to the final accounts of Shiekan Insurance and Reinsurance Company for the fiscal year (2007) and for the fiscal year (2009), we find that the total insurance revenue for the year 2006 was $(174,492,505$ Sudanese pounds) and rose to $(191,635,995$ Sudanese pounds) In the year 2007, and for the year 2009, it was $(223,382,885)$ Sudanese pounds, while it was $(204,319,280)$ Sudanese pounds for the year 2008 , which confirms the increase, if only to a small extent, over the company's revenues. Whereas the profits increased from (22.12 million Sudanese pounds) for the year 2003 to (28.65 million Sudanese pounds) for the year 2004, and from (18.53 million Sudanese pounds) in the year 2007 to (72.965 million Sudanese pounds) for the year 2008 and to (343.689 million Sudanese pounds) ) For the year 2009.

\section{Conclusion}

\section{Recommendations}

In light of these results, the study makes some recommendations that can be summarized as follows:

a. More attention to the level of the company's internal infrastructure for information technology, attention to raising the level of skill and experience of the company's employees in the field of information technology, and the need to find specialized departments to manage and sustain the company's information technology.

b. Explain the extent of the positive impact of information technology applications on the performance level of employees to increase their confidence, interaction, and work to create an entrepreneurial spirit among them by adopting incentives and rewards programs for the distinguished in the modern technical field. 
International Journal of Economics, Business and Accounting Research (IJEBAR)

Peer Reviewed - International Journal

Vol-4, Issue-1, 2020 (IJEBAR)

E-ISSN: 2614-1280 P-ISSN 2622-4771

https://jurnal.stie-aas.ac.id/index.php/IJEBAR

c. The necessity of providing sources of financing for the company by the banks on soft terms and government guarantees to bring more modern technology and work on developing and creating special programs for the company in the field of insurance.

d. Cooperating with local information systems companies to develop the technology due to the blockade conditions that the country suffers from.

e. The company works to create and develop a safe working environment for the technology, and that there is an increase in the level of support provided by the government to companies working in the field of taxes and fees imposed on electronic deals and modern technological products, to enhance the technical capabilities of existing communications and information networks for the company.

\section{Future Studies}

The limitations of this study are stated due to the choice of methodology and focus of the problem researched. Further studies are required in order to investigate the impact of ICT on Insurance sector, to study InsurTech : Infrastructure for New Insurance in (Sudan).

\section{References}

Abdul Motin, Ostagar, Impact of Technology and Innovation in Insurance Sector, International Journal of Management, IT \& Engineering Vol. 8 Issue 12, December 2018.

Annette Gannon, The Impact of Technology on the Insurance Industry, Jul 24, 2018.

Chris Mackechnie, The role of IT in Insurance, http// www.ehow.com.

Gregory Gambone), (Information Technology in the Insurance Sector, http// www.ehow.com.

Karehka Ramey, . Advantages and disadvantages of information technology, http//www. useoftechnology,2012.

Sherif Mahmoud Radwan, The Impact of digital Technologies on Insurance Industry in light of digital transformation, Blom Egypt investments and Insurance Brokerage \& Consultancy, Jan 2019.

Steve Glenn ,The use of IT in Insurance, http// www.ehow.com.

Sidigy, Muhammad Najatullah, Insurance in Islamic Economics, King Abdulaziz University, Scientific Publishing Center, 2nd edition, 1410 (1990).

Zhong An Fintech Institute Min Wang, Hewei Zhou, Quan Zhang, Yuming Zhan , InsurTech: Infrastructure for New Insurance,KPMG CHINA Insurance Service, 2019, KPMG Advisory (China) Limited)

Swiss Re Institute,Technology and insurance: themes and challenges, june, 2017.

Http// www. Binary Egypt.com, IT concept, 7 May 2012. 